\title{
Identification and Elimination of Fluorescent Surface-Damage Precursors on DKDP Optics
}

M.C. Nostrand, S. Thompson, W. Siekhaus, M. Fluss, D. Hahn, P. Whitman, A. Burnham

This article was submitted to

Boulder Damage Symposium XXXIV: Annual Symposium on Optical Materials for High Power Lasers, Boulder, CO

U.8. Departmant of Energy

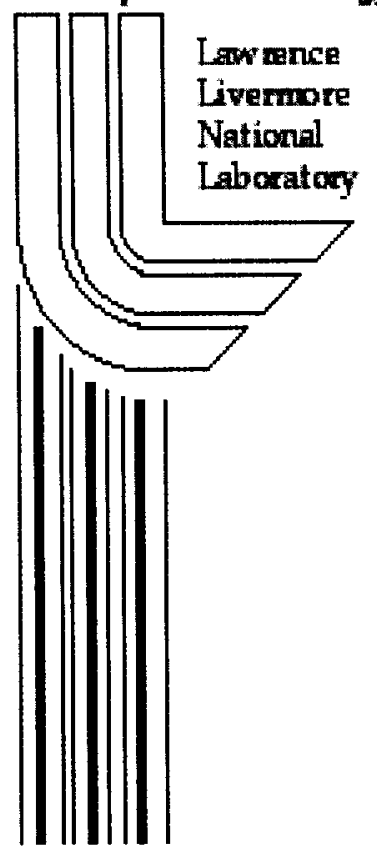
September $16-18,2002$

November 15, 2002 


\section{DISCLAIMER}

This document was prepared as an account of work sponsored by an agency of the United States Government. Neither the United States Government nor the University of California nor any of their employees, makes any warranty, express or implied, or assumes any legal liability or responsibility for the accuracy, completeness, or usefulness of any information, apparatus, product, or process disclosed, or represents that its use would not infringe privately owned rights. Reference herein to any specific commercial product, process, or service by trade name, trademark, manufacturer, or otherwise, does not necessarily constitute or imply its endorsement, recommendation, or favoring by the United States Government or the University of California. The views and opinions of authors expressed herein do not necessarily state or reflect those of the United States Government or the University of California, and shall not be used for advertising or product endorsement purposes.

This is a preprint of a paper intended for publication in a journal or proceedings. Since changes may be made before publication, this preprint is made available with the understanding that it will not be cited or reproduced without the permission of the author.

This report has been reproduced directly from the best available copy.

Available electronically at http://www.doc.gov/bridge

Available for a processing fee to U.S. Department of Energy

And its contractors in paper from

U.S. Department of Energy

Office of Scientific and Technical Information

P.O. Box 62

Oak Ridge, TN 37831-0062

Telephone: (865) 576-8401

Facsimile: (865) 576-5728

E-mail: reports@adonis.osti.gov

Available for the sale to the public from

U.S. Department of Commerce

National Technical Information Service

5285 Port Royal Road

Springfield, VA 22161

Telephone: (800) 553-6847

Facsimile: (703) 605-6900

E-mail: orders@ntis.fedworld.gov

Online ordering: http://www.ntis.gov/ordering.htm

OR

Lawrence Livermore National Laboratory

Technical Information Department's Digital Library

http://www.llnl.gov/tid/Library.html 


\title{
Identification and elimination of fluorescent surface-damage precursors on DKDP optics
}

\author{
M. C. Nostrand*, S. Thompson, W. Siekhaus, M. Fluss, D. Hahn, P. Whitman, and A. Burnham \\ Lawrence Livermore National Laboratory, PO Box 808, L-592, Livermore, CA 94551
}

\begin{abstract}
Fluorescing surface defects that led to damage upon 351-nm laser exposure below $7 \mathrm{~J} / \mathrm{cm}^{2}$ (3-ns) in DKDP optics were reported in these proceedings by this group a year ago. ${ }^{1}$ Subsequent laser damage experiments have correlated the density of these damage precursors to single-point diamond finishing conditions. Every diamond-finishing schedule contains brittle-mode cutting and ductile-mode cutting in a taper-down sequence. Finishing experiments have traced the occurrence of these defects to insufficient ductile-mode removal of subsurface damage incurred during prior brittle-mode cutting. Additionally, a correlation between defect fluorescence, laser-induced damage, and defect morphology has been established. Laser-induced damage tests also suggest a correlation between growth method and damage probability. Current experiments indicate that damage-prone defects can be minimized with the proper choice of diamond finishing conditions.
\end{abstract}

Keywords: DKDP, Laser-induced damage, Fluorescence, Diamond Finishing

\section{INTRODUCTION}

The operation of large-aperture, high-peak-power lasers is often limited by laser-induced damage to the optical components. The surfaces of these optics are most susceptible to the accumulation of contamination and/or defects (for example, during polishing or finishing), and localized damage can occur at the site of the contaminant or defect after absorption of the incident laser light. ${ }^{2,3}$ While a great deal of effort has been invested in improving the damage threshold of the optical surfaces ${ }^{4,5,6}$, some level of damage precursors inevitably remains. This has fueled the need for a non-invasive technique to identify damage precursor sites. Recently, Demos has developed such a technique using fluorescence microscopy. ${ }^{1,7}$ This method exploits the hypothesis that damage precursors absorb and then reradiate light at longer wavelengths, which can be readily imaged using current $\mathrm{CCD}$ technology.

Such a fluorescence system was employed for the purposes identifying surface damage precursors on DKDP crystals used in the harmonic conversion of 1- $\mathrm{m}$ m radiation. The surfaces of these crystals are prepared using single-point diamond turning, ${ }^{8.9}$ which involves slowly translating the crystal across a high-speed flywheel equipped with a diamond tip designed to remove a very shallow layer of material upon each revolution. Accordingly, a set of grooves, or diamond-turning lines, can be observed upon close examination of the surface. Although largely proprietary, a great deal of effort has been aimed at finding cutting parameters (flywheel speed, depth of cut, etc.) that optimize the crystal surface finish in a reasonable amount of time.

Laser-induced (351-nm) surface damage on a DKDP crystal was reported a year ago in these proceedings and was correlated to elliptical-shaped precursors identified using fluorescence microscopy, as shown in Figure 1. In this paper, we examine the extent of these fluorescing precursors in other DKDP crystals, and employ dark-field and atomic-force microscopy in order to determine their nature and origin. Note that we do not address precursors in general in this paper, but limit ourselves to this specific kind of elliptically-shaped defect.

\footnotetext{
'Correspondence: Email: Nostrand1@llnl.gov; Phone: 925422 2712; Fax: 9254225099
} 

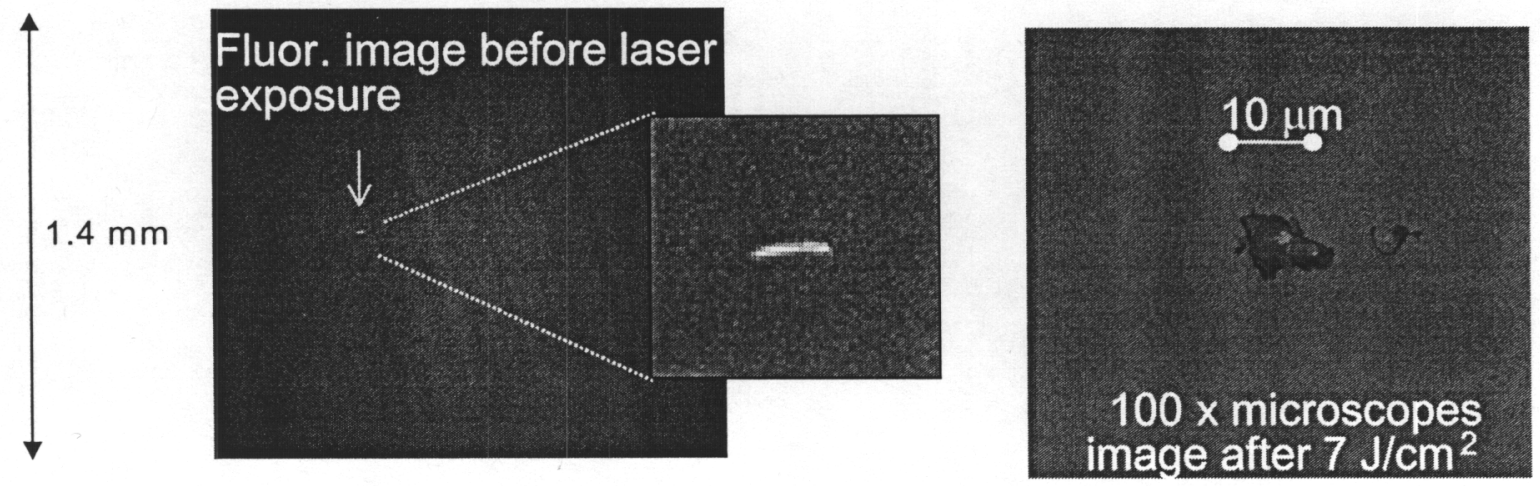

Figure 1. An example of the type of fluorescent surface defect examined in this paper (a), and the resulting damage upon 351-nm laser exposure.

\section{DARK-FIELD MICROSCOPY}

Using the experimental set-up described in Ref. [1], fluorescent defect sites were located on the surface of DKDP crystals. In order to further characterize their nature, these defect sites were subsequently examined under a darkfield microscope. Examples of dark-field images are shown in Figure 2. Upon close examination, it was discovered that features similar to those found at the fluorescent sites occur elsewhere on the sample. These latter features, however, did not fluoresce nor damage upon subsequent laser irradiation.
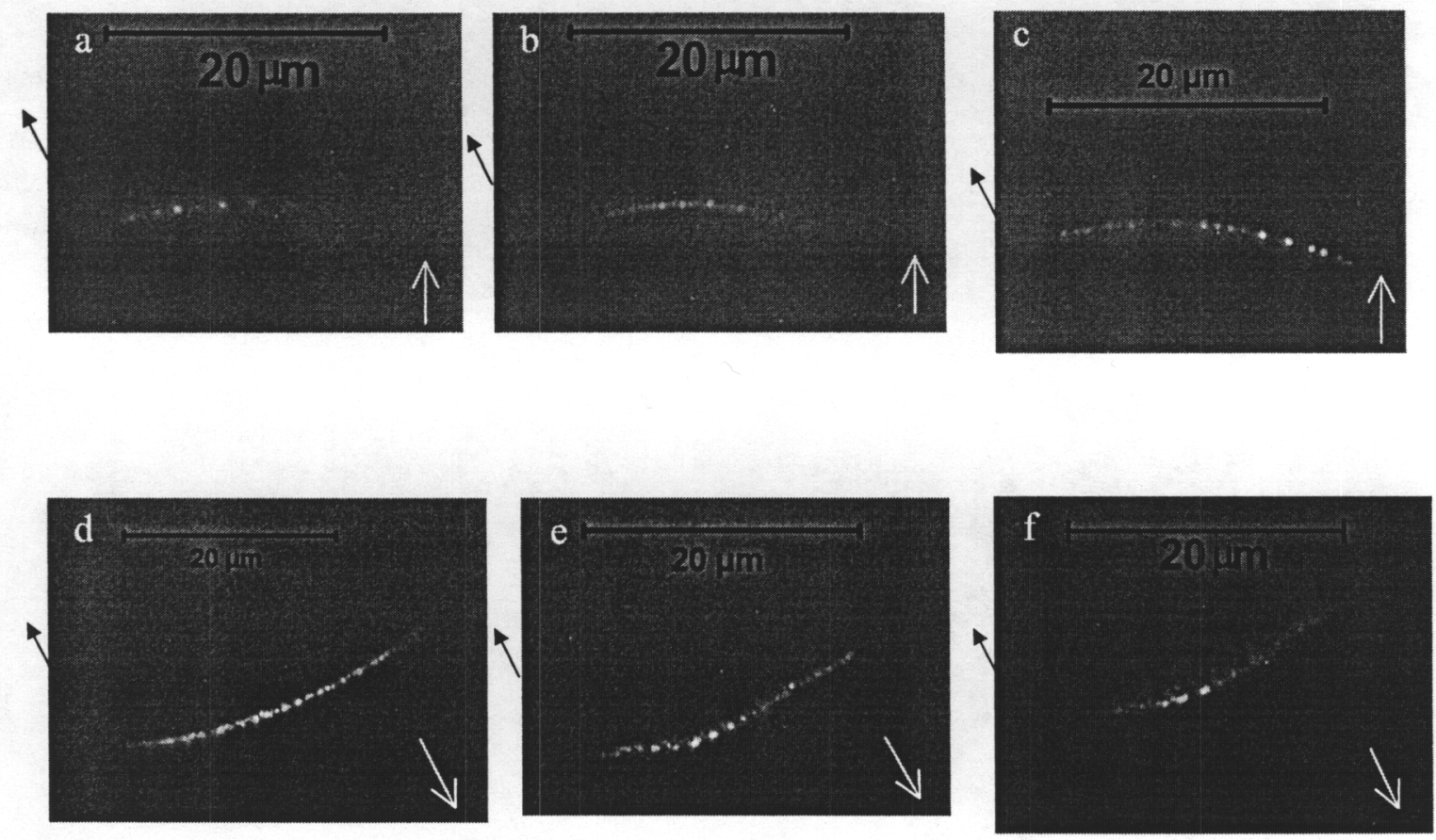

Figure 2. Examples of the surface defects as seen under a dark-field microscope (white-light illumination). Arrows at left indicate direction of crystal axis. Samples (a)-(c) were finished using Machine A, (d)-(f) using Machine B. Arrows at right indicate diamond-tool cutting direction. 
In the examples of Figure 2, images $\mathrm{b}, \mathrm{c}$, and $\mathrm{f}$ exhibited fluorescence, while $\mathrm{a}, \mathrm{d}$, and $\mathrm{e}$ did not. It was observed that typically there are more non-fluorescent than fluorescent features on a given surface. The density of non-fluorescing defects was difficult to quantify, but ranged from $\sim 10 \%$ more (than fluorescing defects) in some crystals to three orders of magnitude more in extreme cases. Each of the defects is $\sim 20$ microns in length and has a slightly curved shape. Each image corresponds to a different DKDP sample. The three top crystals (images a-c) were finished on the same finishing machine (Machine A), whereas the three bottom crystals (images d-f) were finished on Machine B. The orientation of the defects (relative to the c-axis of the crystal, shown) appears to be characteristic for each machine. Since the orientation of the optic relative to the path of the flycutter is also uniquely constrained, these dark-field images suggest the possibility these defects arose during diamond finishing.

\section{ATOMIC FORCE MICROSCOPY}

AFM images of the defects reveal two important observations. First, the defects that exhibited fluorescence were all associated with some sort of surface rupture, such as that shown in Figure 3, while the non-fluorescing defects revealed no such surface rupture. This suggests that the fluorescence might be caused by some contaminant that enters the rupture, or by some electronic defect created by the rupture. Second, all defects were oriented perpendicular to the diamond-turning lines, suggesting diamond finishing as the origin of the defect. Indeed, one could imagine these defects being cracks/ruptures formed in the tensile wake of the diamond tool as it scrapes across the crystal surface.

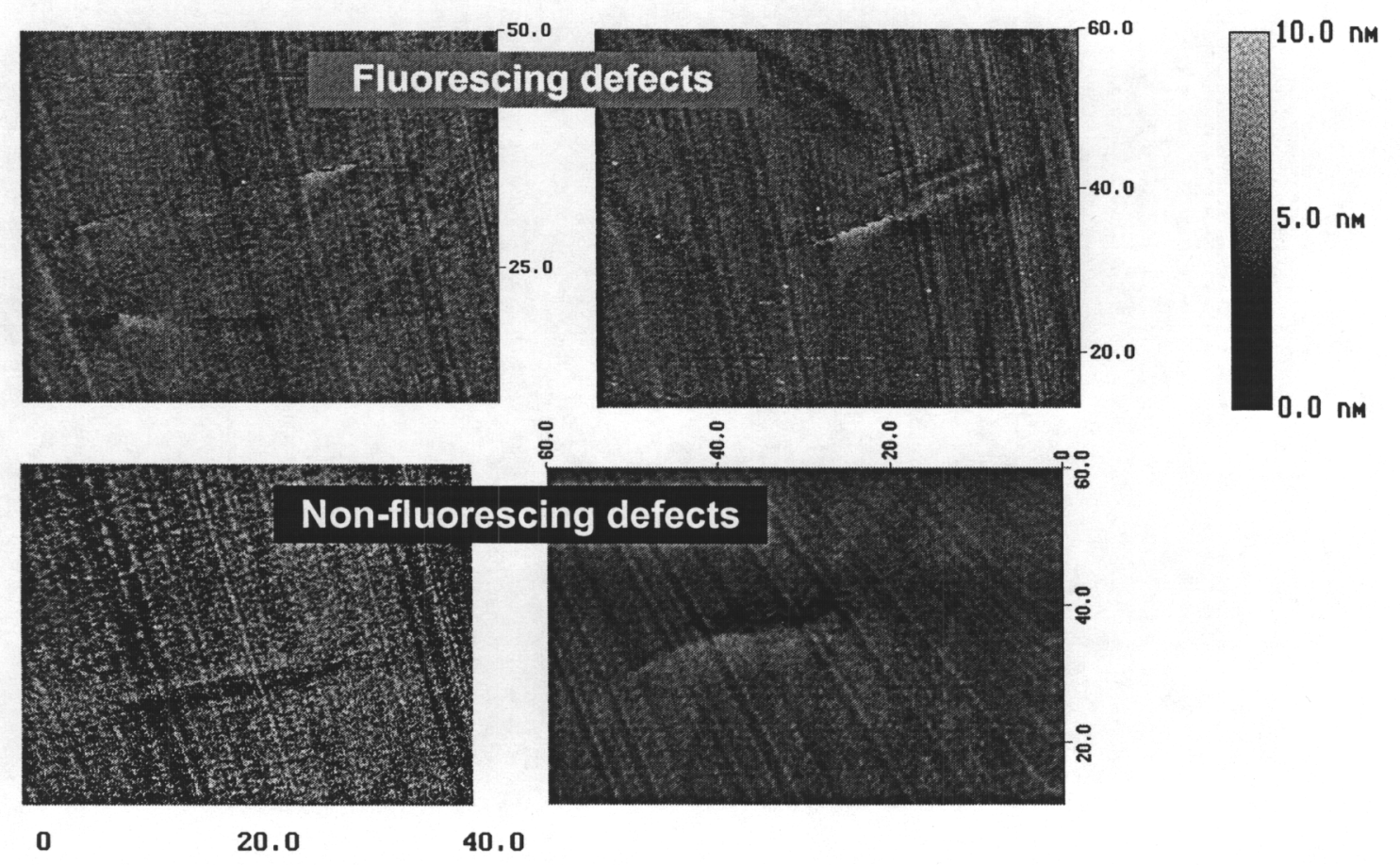

Figure 3. AFM images of (a) fluorescent and (b) non-fluorescent surface defects. Fluorescent defects are associated with holes or ruptures in the surface, while non-fluorescing features either have not ruptured at the surface, or have been "filled in" since the original event.

\section{FLUORESCENCE MAPPING AND LASER DAMAGE TESTING OF DKDP CRYSTALS}

Using the experimental set-up described in Ref. [1], many DKDP crystals were fluorescence mapped to determine fluorescent-defect density, see Table 1. Fluorescence images are acquired with a nitrogen cooled scientific grade 
CCD camera (Princeton Instruments) by exciting the sample with $\sim 1$ watt of $351-\mathrm{nm}$ radiation. Filters are used to accumulate fluorescence data in the $400-800 \mathrm{~nm}$ range. Each image covers approximately $1.4-\mathrm{mm} \times 1.4-\mathrm{mm}$. The depth of focus of the imaging system, as well as the resolution of the images, is a few microns. Large (square) areas of a sample are mapped automatically by software that steps the sample in a serpentine pattern and records each image. These images are fed into another software program (IPLab) that was programmed to identify fluorescent defects. Identification of defects is specified by size ( $\sim 10-30$ microns), eccentricity ( $>0.90$ generally), and orientation (perpendicular to diamond turning lines) of the fluorescent feature.

A subset of the crystals in Table 1 was damage tested using a $351-\mathrm{nm}, 3.0-\mathrm{ns}$, $3-\mathrm{cm}$ diameter laser source. Locations of surface-damage sites could then be correlated to the locations of damage precursors. In general, a high correlation between surface damage and fluorescing defect was found, whereas the same could not be said for the non-fluorescing (but otherwise similar) defects.

Table 1. Results of mapping and damage testing of DKDP crystals. For growth method, $R$ indicates Rapid Growth while $C$ denotes Conventional growth. The last two columns indicate what finishing machine was used, and what schedule (set of cutting parameters) was used.

\begin{tabular}{|c|c|c|c|c|c|c|c|}
\hline $\begin{array}{c}\text { Sample } \\
\text { ID }\end{array}$ & $\begin{array}{l}\text { Growth } \\
\text { Method }\end{array}$ & $\begin{array}{c}\text { Number of } \\
\text { fluorescing } \\
\text { defects }\end{array}$ & $\begin{array}{c}\text { Area } \\
\text { examined } \\
\left(\mathrm{cm}^{2}\right)\end{array}$ & $\begin{array}{c}\text { Density of } \\
\text { fluorescing } \\
\text { defects }\left(\mathrm{cm}^{-2}\right)\end{array}$ & $\begin{array}{c}\text { Density of } \\
\text { damaging } \\
\text { defects at 6-8 } \\
\mathrm{J} / \mathrm{cm}^{2}\left(\mathrm{~cm}^{-2}\right)\end{array}$ & $\begin{array}{c}\text { Finishing } \\
\text { machine }\end{array}$ & $\begin{array}{l}\text { Cutting } \\
\text { schedule }\end{array}$ \\
\hline $20 \mathrm{~A} 15 \mathrm{D}-3$ & $\mathrm{R}$ & 7 & 9 & 0.8 & Not Tested & $\mathrm{A}$ & $\bar{P}$ \\
\hline BD8-10 & $\mathrm{R}$ & 65 & 36 & 1.8 & 0.7 & $\mathrm{~A}$ & $\mathrm{P}$ \\
\hline BD8-4 & $\mathrm{R}$ & 10 & 9 & 1.1 & Not Tested & $\mathrm{A}$ & $\mathrm{P}$ \\
\hline BD8-5 & $\mathrm{R}$ & 36 & 7 & 5.1 & 1.4 & $\mathrm{~B}$ & G2 \\
\hline BD8-8 & $\mathrm{R}$ & 167 & 27 & 6.2 & 3.4 & B & G2 \\
\hline BD8-8M & $\mathbf{R}$ & 5 & 9 & 0.6 & Not Tested & A & $\mathrm{P}$ \\
\hline BD8-9 & $\mathbf{R}$ & 3 & 7 & 0.4 & Not Tested & A & G1 \\
\hline CD41-3 & $\mathrm{R}$ & 45 & 36 & 1.3 & 0.2 & A & $\mathrm{P}$ \\
\hline CD43-2 & $\mathbf{R}$ & 14 & 27 & 0.5 & Not Tested & $\mathrm{A}$ & $\mathbf{P}$ \\
\hline LL1 1-1 & C & 24 & 45 & 0.5 & $<0.07$ & $\mathrm{~A}$ & $\mathbf{P}$ \\
\hline LL11-2 & $\mathrm{C}$ & 40 & 18 & 2.2 & $<0.02$ & A & $\mathrm{P}$ \\
\hline LL6-1 & $\mathrm{C}$ & 29 & 27 & 1.1 & $<0.05$ & B & G1 \\
\hline LL6-4 & $\mathrm{C}$ & 0 & 27 & $<0.04$ & $<0.02$ & A & $\mathbf{P}$ \\
\hline LL6-6 & $\mathrm{C}$ & 40 & 27 & 1.5 & $<0.02$ & A & $\mathbf{P}$ \\
\hline LL11-c & $\mathrm{C}$ & 0 & 27 & $<0.04$ & $<0.02$ & $\mathrm{~A}$ & RI \\
\hline
\end{tabular}

Table 1 indicates that damage in these crystals was limited to two rapid-growth crystals finished by Machine B and schedule G2, and two rapid-growth crystals finished on Machine A and schedule P. All crystals finished using Machine B but not schedule G2 are damage free, as are all conventional-growth crystals finished on Machine A and schedule $P$. These results suggest the diamond-finishing schedule and the method of growth play an important role in the creation of the fluorescent precursors.

\section{SINGLE-POINT DIAMOND FINISHING}

Single-point diamond turning of large KDP and DKDP crystals has been used extensively to produce high damage threshold surfaces while meeting crystal orientation, flatness, and other optical performance parameters. The Appendix defines important concepts in diamond finishing that will be useful in understanding the possible cause of the fluorescent defects, such as feed per revolution (FPR), depth of cut (DOC), and chip thickness (CT). Crystal surfaces are finished using a particular cutting schedule that specifies values for these (and other) parameters.

An important concept in diamond finishing is that of ductile- vs. brittle-mode cutting. ${ }^{10}$ In order to finish a surface in reasonable time, each cutting schedule contains brittle-mode and ductile-mode cutting in a taper-down sequence; see Figure 4. Brittle-mode machining is used in the initial stages to control subsurface damage from previous operations. The brittle-mode material removal mechanism is tensile failure, so that pits and cracks are created at/near the surface. For the finishing schedules used in this work, the depth of brittle-mode damage is proportional to the chip thickness (which can be controlled by FPR and/or DOC). Ductile-mode machining is much slower than 
brittle-mode, and is used in the final stages of finishing. The material removal mechanism is shear, so that no pits or cracks are formed. In brittle materials, the ductile regime applies only to very small chip thickness.

Experiments were performed on small (2-inch) DKDP samples to investigate depth of damage vs. chip thickness. These samples were finished with a schedule designed to vary chip thickness, and depth of damage was determined by subsequently cutting a wedge (in the ductile mode) in the sample, and noting the depth at which no more damage was apparent under a microscope. Figure 5 shows a clear transition between ductile and brittle mode. In order to investigate the distribution of depth of the damage created, one of the wedged samples was used to quantify the number of (non-fluorescing) defects as a function of depth. This data shown in

Figure 6, indicates a maximum fracture depth of $\sim 20 \mu \mathrm{m}$.

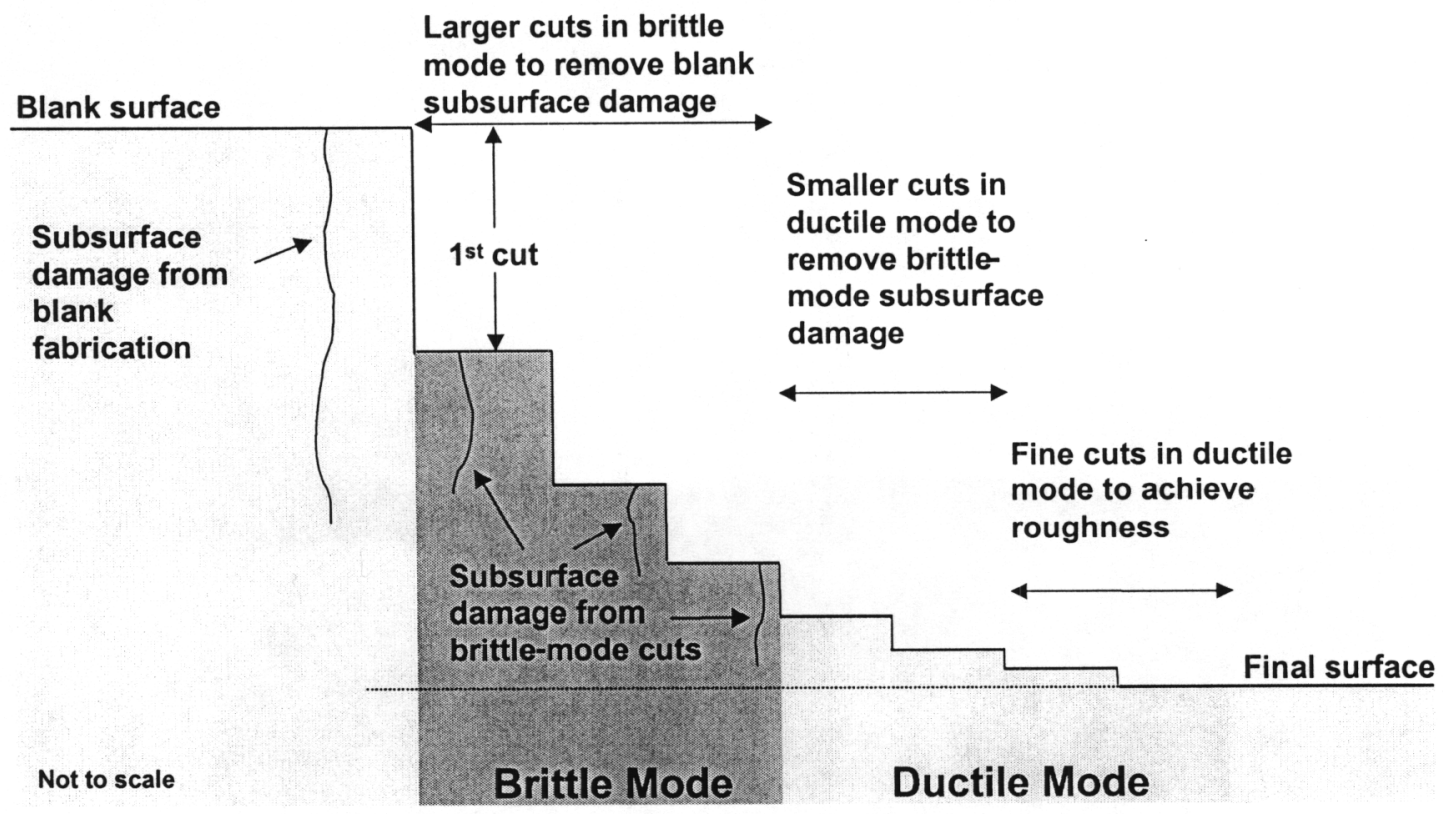

Figure 4. An example of a generic cutting schedule showing ductile- and brittle-mode machining.

The hypothesis for the origin of the fluorescent surface defects is that they derive from subsurface damage created during brittle-mode cutting which is not removed during subsequent ductile-mode cutting. In other words, the particular cutting schedule did not allow enough ductile-mode cutting in the final stages to remove all of the subsurface damage created during brittle-mode cutting during previous stages. The brittle-mode damage is created in the tensile wake of the diamond tool as it traverses the crystal surface.

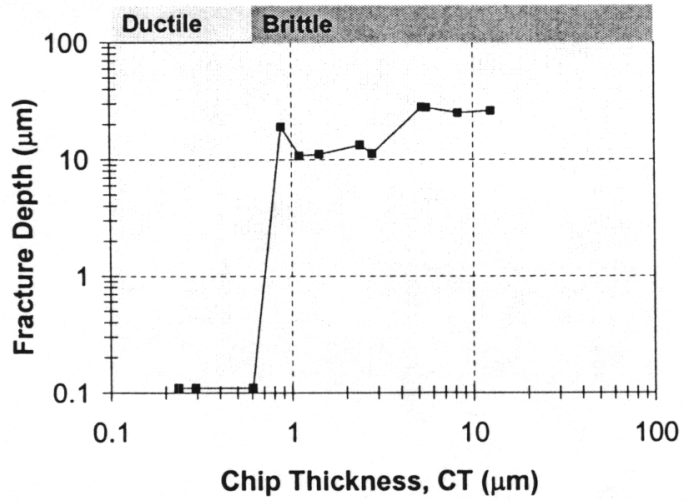

Figure 5. Fracture depth vs. chip thickness for DKDP samples showing the transition between ductile and brittle regimes. A fracture depth of $0.1 \mu \mathrm{m}$ was plotted when no fractures were found.

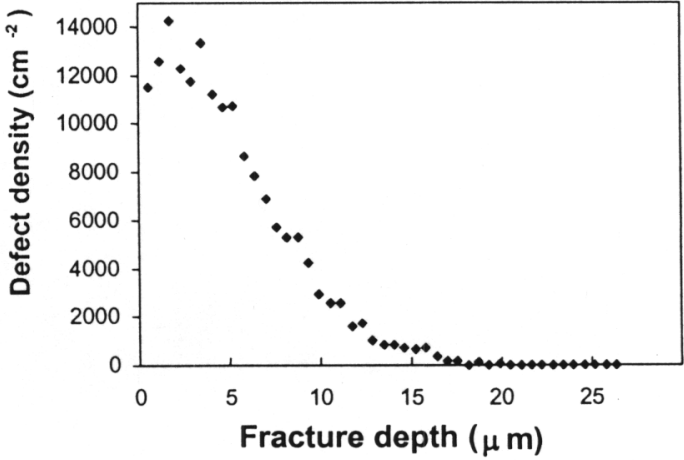

Figure 6. The distribution of fracture depths for a typical brittle-mode cut. 


\section{RELATIONSHIP BETWEEN CUTTING SCHEDULE AND FLUORESCENT DEFECTS}

Using the experimental data relating chip thickness and fracture depth for a given finishing schedule, the amount of residual subsurface damage was calculated for each of the finishing schedules identified in Table 1. For each pass on the finishing machine, the depth of damage and the total remaining material yet to be removed can be calculated. If the cumulative ductile material removal is greater than the depth of damage introduced during the previous brittlemode cuts, then the final distance from the subsurface damage to the finished surface will be positive - i.e. all brittle fracture should be removed. Conversely, if insufficient ductile material removal occurs, and then the distance from the subsurface damage to the finished surface is 'negative' - i.e. remnants of the damage remain. Table 2 shows a sample calculation for cutting schedule ' $R 1$ '. Table 3 tabulates data for all the finishing schedules in this study and shows a strong correlation between the residual subsurface damage depth and the observed density of 'smile' fluorescent defects.

Table 2. Sample calculation of residual damage depth for finishing schedule $\mathbf{G} 2$.

\begin{tabular}{|c|c|c|c|c|}
\hline $\begin{array}{c}\text { Finishing } \\
\text { Pass \# }\end{array}$ & $\begin{array}{c}\text { Predicted } \\
\text { Subsurface } \\
\text { Damage Depth } \\
(\mu \mathrm{m})\end{array}$ & $\begin{array}{c}\text { Distance from } \\
\text { Damage to } \\
\text { Finished } \\
\text { Surface } \\
(\mu \mathrm{m})\end{array}$ & $\begin{array}{c}\text { Chip } \\
\text { Thickness } \\
(\mu \mathrm{m})\end{array}$ & $\begin{array}{c}\text { Distance to } \\
\text { Finished } \\
\text { Surface After } \\
\text { cut } \\
(\mu \mathrm{m})\end{array}$ \\
\hline \hline 1 & 10.9 & 6.3 & 16.5 & 17.2 \\
\hline 2 & 9.75 & -0.05 & 20.5 & 9.7 \\
\hline 3 & 0 & -0.05 & 17 & 7.2 \\
\hline 4 & 0 & -0.05 & 17 & 4.7 \\
\hline 5 & 0 & -0.05 & 17 & 2.2 \\
\hline 6 & 0 & -0.05 & 10 & 1 \\
\hline 7 & 0 & -0.05 & 10.3 & 0.5 \\
\hline 8 & 0 & -0.05 & 19.4 & 0 \\
\hline & \multicolumn{3}{|r|}{ Total depth removed: } & $29.7 \mu \mathrm{m}$ \\
\hline & & & & \\
\hline
\end{tabular}

Table 3. Comparison of residual brittle-mode damage depth for the tested finishing schedules.

\begin{tabular}{|c|c|c|c|c|}
\hline $\begin{array}{c}\text { Finishing } \\
\text { Schedule }\end{array}$ & $\begin{array}{c}\text { Total depth of } \\
\text { material } \\
\text { removed } \\
(\mu \mathrm{m})\end{array}$ & $\begin{array}{c}\text { Depth of material } \\
\text { removed in ductile } \\
\text { mode } \\
(\mu \mathrm{m})\end{array}$ & $\begin{array}{c}\text { Estimated distance for } \\
\text { subsurface damage to } \\
\text { optic surface* } \\
(\mu \mathrm{m})\end{array}$ & $\begin{array}{c}\text { Fluorescent defect } \\
\text { density of BD8 crystals } \\
\left(\mathbf{c m}^{-2}\right)\end{array}$ \\
\hline G1 & 29.7 & 4.7 & $\sim 6$ & 0.4 \\
\hline R1 & 29.7 & 9.7 & $\sim 0$ & 0 \\
\hline P & 29.7 & 9.8 & $\sim-1$ & $1.8,1.1,0.6$ \\
\hline G2 & 29.7 & 4.7 & $\sim-6$ & $5.1,6.2$ \\
\hline
\end{tabular}

* Estimated using most probable brittle-mode crack depth of $11 \mu \mathrm{m}$ 


\section{DISCUSSION}

As seen in Table 1, the correlation between fluorescent defects and laser damage was limited to two rapid-growth crystals finished using schedule G2 on Machine B and two rapid-growth crystals finished using Schedule P on Machine A. No fluorescening defects damaged on the six conventional-growth crystals which were exposed to laser fluences up to $8 \mathrm{~J} / \mathrm{cm} 2$ even though similar densities of fluorescing defects did provide laser damage precursors on rapid-growth crystals. Fluorescing defect densities appear similar for crystals machined by the same cutting schedule on the same machine from the same bulk material. For instance, 15-cm samples BD8-10 and BD8-4, and 5-cm sample BD8-8M were machined from the same rapid-growth boule (BD8), using finishing schedule $P$ on Machine A, and all three crystals have $\sim 1-2$ fluorescing defects $/ \mathrm{cm}^{2}$. 15-cm samples BD8-5 and BD8-8 which were machined from the same rapid-growth boule (BD8), but using a more aggressive finishing schedule on Machine B, have 2 - 3 times the fluorescing defect density of the more conservatively finished BD8-4 and BD8-10. 15-cm sample BD8-9, finished using the most conservative schedule (greatest ductile-mode material removal below the expected depth of the brittle-mode induced damage) has the fewest fluorescing defects - more than ten times fewer defects than BD8-5 and BD8-8. These results are consistent with the hypothesis that the diamond-finishing schedule and the method of growth play an important role in the creation and damage-resistance of the fluorescent precursors.

\section{CONCLUSION}

A specific defect morphology that can lead to laser-induced surface damage on diamond-finished DKDP optics has been studied using optical and atomic force microscopy. Two varieties of such defects exist, those that fluoresce and those that do not. A high correlation between laser-induced damage and fluorescent defects in rapid-growth DKDP crystals has been observed. In this study, we have not observed laser-induced damage from fluorescing precursors in conventionally grown crystals. Also, fluorescent defects have been linked to a ruptured surface, whereas nonfluorescing defects exhibit no such rupture. It is proposed that the same mechanism that leads to fluorescence also couples the laser energy into the crystal and induces the laser damage. Experimental verification of the onset of brittle-mode removal and the depth of fractures produced by such removal techniques has proven valuable for predicting finishing schedules which produce laser-damage-resistant DKDP surfaces. Elimination of laser damage precursors involves proper finishing schedule management to assure sufficient ductile-mode cutting in the final finishing stages to completely remove damage generated in earlier brittle-mode fabrication steps.

\section{ACKNOWLEDGEMENTS}

We greatly appreciate the efforts of Tim Weiland, Jim Vickers and Wally Sell for the operation of the Optical Sciences Laser in the damage-testing phase of this work. This work was performed under the auspices of the U.S. Department of Energy by the University of California, Lawrence Livermore National Laboratory under contract No. W-7405-Eng-48.

\section{REFERENCES}

1 S.G. Demos, M.C. Nostrand, M. Staggs, C.W. Carr, D. Hahn, M.R. Kozlowski, L. Sheehan, C. Battersby, A. Burnham, "Investigation of fluorescence microscopy as a tool for noninvasive detection and imaging of damage precursors at 351-nm," Laser-Induced Damage in Optical Materials: 200I, Proc. SPIE Volume 4679, pp. 347-358 (2002).

2 M.D. Feit, A.M. Rubenchik, D. Faux, R. Riddle, A. Shapiro, D.C. Elder, B. M. Penetrante, D. Milam, F.Y. Genin, and M.R. Kozlowski, "Modeling of laser damage initiated by surface contamination," Laser-Induced Damage in Optical Materials: 1996, Proc. SPIE Volume 2966, pp. 417-424 (1997).

3 N. Bloembergen, "Role of cracks, pores, and absorbing inclusions on laser induced damage thresholds at surfaces of transparent dielectrics," Appl. Opt. 12, pp. 661-664 (1973).

4 J.A. Ringlien, N.L. Boling, and G. Dube, "An acid treatment for raising the surface damage threshold of laser glass," App. Phys. Lett. 25, pp. 598-600 (1974).

5 R.A. House, J.R. Bettis, and A.H. Guenther, "Efficacy of ion polishing optical surfaces," Appl. Opt. 16, pp. 1486-1488 (1977).

6 A. K. Burnham, L. Hackel, P. Wegner, T. Parham, L. Hrubesh, B. Penetrante, P. Whitman, S. Demos, J. Menapace, M. Runkel, M. Fluss, M. Feit, M. Key, T. Biesiada, "Improving 351-nm damage performance of large-aperture fused silica and DKDP optics," Laser-Induced Damage in Optical Materials: 2001, SPIE Volume 4679, pp. 173-185 (2002). 
7 S.G. Demos and M. Staggs, "Application of fluorescence microscopy for noninvasive detection of surface contamination and precursors to laser-induced damage," Appl. Opt. 41, pp. 1977-1983 (2002).

8 T.T. Saito, "Diamond Turning of Optics: The Past, the Present, and the Exciting Future," Opt. Eng. 17, pp. $570-573$ (1978).

9 B.A. Fuchs, P.P. Hed, and P.C. Baker, "Fine diamond turning of KDP crystals," Appl. Opt. 25, pp. 1733-1735 (1986).

10 W.S. Blackley and R.O. Scattergood, "Ductile-regime machining model for diamond turning of brittle materials," Precision Engineering 13, pp. 95-103 (1991).

\section{APPENDIX}

Figure 7 below illustrates the following concepts applicable to single-point diamond turning of DKDP crystals:

\section{Depth of Cut (DOC)}

The depth from the original surface that the diamond tool penetrates into the crystal

\section{Feed Per Revolution (FPR)}

The lateral distance the crystal has moved upon one revolution of the flywheel

\section{Chip Thickness (CT)}

The maximum thickness of the chip cut by a single sweep of the tool, calculated using the DOC and FPR

\section{Cutting Schedule}

The recipe for finishing a crystal surface, including number cuts, and the FPR and DOC for each cut

a)

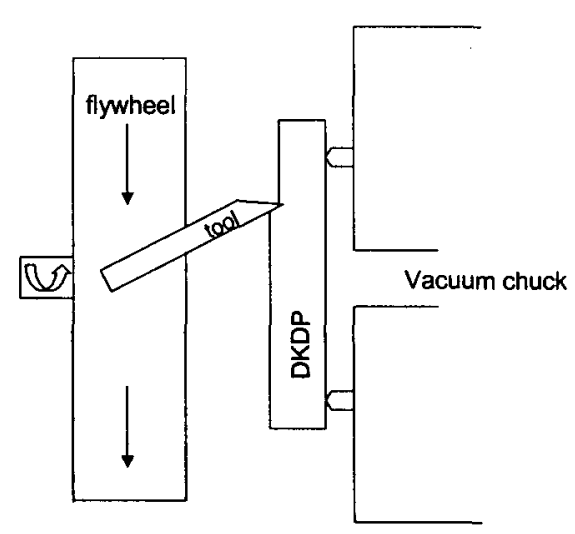

c)

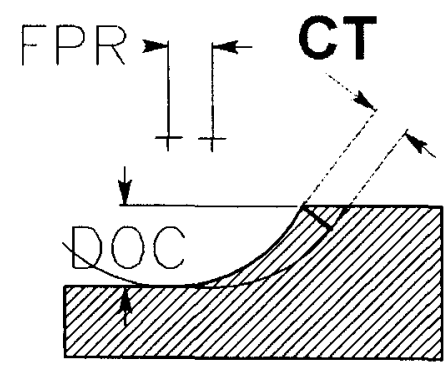

b)

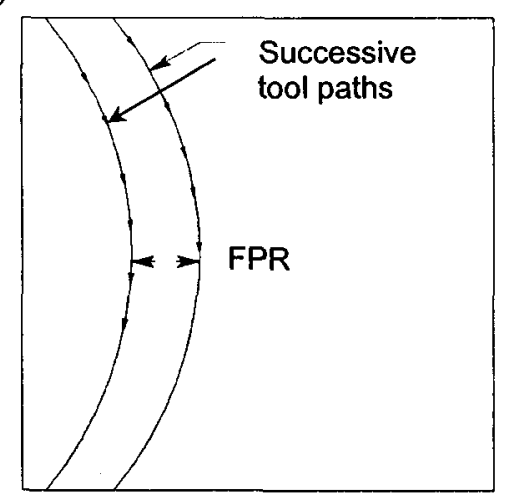

d)

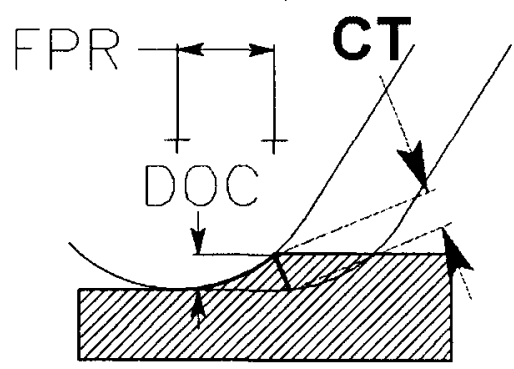

Figure 7. Diamond turning basics (not to scale). (a) side-view of a crystal during finishing showing the flywheel, diamond-tipped cutting tool, DKDP sample, and vacuum chuck mount. (b) frontal view of a crystal illustrating FPR. (c) and (d) side view of a crystal showing DOC, FPR, and CT. Both figures have the same chip thickness, but different FPR and DOC. 